\title{
Experiencia de Usuario + Web Responsivo: Un Estudio desde la Perspectiva de un Enfoque Integrado
}

\author{
User eXperience + Responsive Web: A Study from the Perspective \\ of an Integrated Approach
}

\author{
Paola B. Vidal ${ }^{1}$, Adriana Martin ${ }^{2}$ \\ paolabvidal@gmail.com, adrianaelba.martin@gmail.com \\ ${ }^{1}$ Alumna Desarrollo de Aplicaciones Web/ Ingeniería en Sistemas \\ ${ }^{2}$ Docente Dpto. de Cs. Exactas y Naturales/ Investigador Instituto de Tecnología Aplicada \\ ${ }^{1,2}$ Unidad Académica Caleta Olivia (UACO) \\ Universidad Nacional de la Patagonia Austral (UNPA)
}

Recibido: 31/10/2019. Aceptado: 12/12/2019

\begin{abstract}
RESUMEN
Al desarrollar un producto web (sitio, aplicación móvil o app), considerar la eXperiencia de Usuario (UX) es un factor clave al éxito del proceso de diseño. Un buen diseño de interfaz puede permitirle al usuario mantener una interacción más simple y eficiente con el producto web. Mientras que el diseño de la eXperiencia de Usuario (UX) es el proceso de lograr su satisfacción, mejorando la usabilidad, la facilidad de uso y el placer proporcionados en su interacción con el producto web. Por otra parte, si además, el producto ofrece propiedades de Diseño Web Responsivo (RWD), es mucho más probable que los visitantes desde dispositivos móviles experimenten una interacción más positiva que los incite a visitar y utilizar el producto nuevamente. Existen ciclos ágiles que consideran la UX en el desarrollo de un productos web, pero no incluyen específicamente propiedades que lo tornen responsivo a lo efectos de contribuir a la satisfacción del usuario que utiliza multidispositivos para interactuar con dicho producto. Por otra parte, con la aparición de la filosofía RWD, surgen varias propuestas para contribuir a que un producto sea responsivo, facilitando su uso desde cualquier tipo de dispositivo. Ensamblar las fortalezas de UX y el RWD en el desarrollo de un producto web parece ser un enfoque prometedor para alcanzar la satisfacción de sus usuarios.

En este trabajo se realizan análisis del estado-del-arte de los ciclos ágiles de desarrollo que consideran la UX, como así también, de las propuestas que consideran características multidispositivo en los productos web a desarrollar. De esta manera, se propone un enfoque integrador. El enfoque ensambla los beneficios del desarrollo multidispositivo en el ciclo de diseño UX, basados en la hipótesis de que el diseño responsivo contribuye a mejorar la UX en el desarrollo de producto web.
\end{abstract}

Palabras clave: eXperiencia de Usuario (UX); Diseño Web Responsivo (RWD); Ciclos Ágiles; Enfoque Integrado, Diseño UX Multidispositivo.

\begin{abstract}
When developing a web product (site, mobile application or app), considering User Experience (UX) is a key factor in the success of the design process. A good interface design can allow the user to maintain a simpler and more efficient interaction with the web product. While the design of the User Experience (UX) is the process of achieving your satisfaction, improving the usability, ease of use and pleasure provided in your interaction with the web
\end{abstract}


product. On the other hand, if the product also offers Responsive Web Design (RWD) properties, visitors from mobile devices are much more likely to experience a more positive interaction that encourages them to visit and use the product again. There are agile cycles that consider the UX in the development of a web product. However, in order to contribute to the satisfaction of users interacting through multi-device, these cycles do not specifically include properties to make the product responsive. On the other hand, with the emergence of the RWD philosophy, several proposals arise to help make a product responsive, facilitating its use from any type of device. Joining the strengths of UX and RWD in the development of a web product seems to be a promising approach to reach their users' satisfaction.

This work analyzes the state-of-the-art of agile development cycles that consider the UX, as well as the proposals that consider multi-device features in the web products to be developed. In this way, an integrated approach is proposed. The approach joins the benefits of multidevice development in the UX design cycle, based on the hypothesis that responsive design helps improve UX in web product development.

Keywords: User Experience (UX); Responsive Web Design (RWD); Agile Cycles; Integrated Approach, UX Multi-Device Design.

\section{INTRODUCCIÓN}

El uso de múltiples productos web, genera que la tecnología invada constantemente distintos aspectos de nuestra vida, desde el trabajo hasta el ocio, y es la eXperiencia usando un producto, es decir, cómo este es capaz de resolver nuestras necesidades de forma eficiente, amigable y fluida; la que determinará la permanencia del usuario en el producto web y que éste sea incitado a visitarlo nuevamente.

La "eXperiencia del usuario" abarca todos los aspectos de la interacción del usuario final con la empresa, sus servicios y sus productos. El primer requisito para una UX ejemplar es satisfacer las necesidades exactas del cliente, sin problemas ni molestias. Luego viene la simplicidad y la elegancia que producen productos que son una alegría de poseer, una alegría de usar. La verdadera UX va mucho más allá de dar a los clientes lo que dicen que quieren o de proporcionar funciones de lista de verificación. Para lograr una UX de alta calidad en las ofertas de una empresa, debe haber una fusión perfecta de los servicios de múltiples disciplinas, que incluyen ingeniería, marketing, diseño gráfico e industrial, y diseño de interfaz (Nielsen Norman Group).

Es importante distinguir la eXperiencia total del usuario de la interfaz de usuario (UI), aunque la UI es obviamente una parte extremadamente importante del diseño. Como ejemplo, si se considera un producto web con críticas de películas. Incluso si la UI para encontrar una película es perfecta, la UX será pobre para un usuario que quiera información sobre un pequeño lanzamiento independiente si la base de datos subyacente solo contiene películas de los principales estudios.

También debemos distinguir entre UX y usabilidad: de acuerdo con la definición de usabilidad, es un atributo de calidad de la interfaz de usuario, que cubre si el sistema es fácil de aprender, eficiente de usar, agradable, etc. Nuevamente, esto es muy importante, y nuevamente la eXperiencia total del usuario es un concepto aún más amplio (Nielsen Norman Group).

La filosofía de Diseño Web Responsivo ayuda a mejorar la UX, porque permite que los productos web sean diseñados para ser robustos, adaptarse a los tamaños de pantalla y resoluciones de cada dispositivo dinámicamente; adaptando la aplicación al tamaño de la pantalla de cualquier dispositivo, sin que se vea afectada la estructura y diseño, logrando de esta manera 
que el usuario se sienta a gusto con el producto sin importar desde donde está accediendo, asegurando que su experiencia de navegación se positiva en cualquier dispositivo.

Si bien, desde su aparición en el 2011, el diseño responsivo ha ofrecido flexibilidad para adaptar la interfaz de usuario de un único producto web para manejar un rango de resolución diferente para que el usuario en diferentes dispositivos pueda experimentar el mismo diseño de producto web esperado; desafortunadamente, todavía no se ha realizado ninguna investigación para demostrar si mantiene con éxito la calidad de la eXperiencia del usuario en muchos dispositivos, aunque hay muchos artículos técnicos sobre los resultados de los motores de búsqueda (Hidayanto, 2014).

Es importante comprender que el diseño responsivo es sólo una herramienta. Si bien la aplicación del diseño responsivo tiene muchas ventajas al desarrollar para multi-dispositivos, el uso de esta valiosa herramienta no garantiza una experiencia útil y exitosa (al igual que el uso de una receta gourmet no garantiza la creación de una comida magnífica). Los equipos deben centrarse en los detalles de contenido, diseño y rendimiento para apoyar a los usuarios en todos los dispositivos (Nielsen Norman Group, 2014).

Este trabajo de investigación fue desarrollado en el marco de la asignatura DESARROLLO DE APLICACIONES WEB perteneciente a la carrera Ingeniería en Sistemas, dictada en la UNPA-UACO y tiene como propósito: (i) realizar un análisis del estado del arte de los ciclos de desarrollo más reconocidos que consideran la eXperiencia de usuario, como así también de los marcos de trabajo propuestos para aplicaciones multidispositivo; y (ii) efectuar una comparación entre los procesos y marcos de trabajo mencionados, en pos de proponer un enfoque integrado, que permita llevar adelante la construcción de un producto diseñado bajo los lineamientos propuestos por el diseño responsivo y que considere la eXperiencia de usuario, apoyándonos en la hipótesis de que el RWD contribuye al desarrollo de un producto con buena eXperiencia de usuario.

Este documento se organiza de la siguiente manera: en la Sección 2 se mencionan las estadísticas que aseveran el crecimiento del internet móvil, y por tal la importancia de construir productos responsivos. En la Sección 3 se define el concepto de eXperiencia de usuario y se describen brevemente los ciclos ágiles de desarrollo, bajo los cuales se desarrollará la propuesta. En la Sección 4 se define el concepto de Diseño Web Responsivo y se detallan brevemente las propuestas de trabajo para su aplicación. En la Sección 5 se propone un enfoque integrado, que considera UX y RWD en el proceeso de desarrollo de un producto web. Finalmente, en la Sección 6 se describen las conclusiones y trabajo futuro de la investigación realizada.

\section{CRECIMIENTO DEL INTERNET MOVIL}

Cada vez son más las personas que navegan por internet utilizando dispositivos móviles, en comparación con una computadora de escritorio.

Según lo reportado por Statista, el uso de Internet móvil se ha abierto camino en la vida diaria de los usuarios de teléfonos inteligentes y tabletas, permitiendo a los consumidores acceder y compartir información sobre la marcha. Hay un futuro prometedor para el uso de Internet móvil, ya que se prevé que el tráfico de datos móviles globales aumente casi siete veces entre 2017 y 2022. Según los datos de abril de 2019, la población móvil mundial ascendió a 4 mil millones de usuarios únicos. A partir de febrero de 2019, los dispositivos móviles representaban el $48 \%$ de las visitas a páginas web en todo el mundo, con los primeros mercados móviles como Asia y África liderando el paquete. Nigeria registró la tasa más alta de tráfico de Internet proveniente de dispositivos móviles; seguido por India, Ghana y Kenia. Las Américas y Europa tienen la tasa de penetración de suscripción de banda ancha móvil más alta, alrededor del $97.1 \%$ y el $93.6 \%$, respectivamente. En 2018, el promedio mundial se situó en casi el 69,3\% (Statista, 2019). 
En la siguiente tabla se mencionan las estadísticas tenidas en cuenta, que aseveran el crecimiento de Internet móvil en el mundo:

Tabla 2.1: Estadísticas del uso de Internet móvil en todo el mundo.

\section{Estadísticas del uso de Internet móvil en todo el mundo}

\section{Audiencias móviles y acceso}

Población digital mundial a partir de julio de 2019 (Statista, 2019).

Tarifa de suscripción a Internet de banda ancha móvil 2018, por región (Statista, 2019).

Parte del tráfico del producto web de teléfonos móviles en todo el mundo 2018 (Statista, 2019).

Suscripciones de banda ancha móvil por cada 100 habitantes en 2017, por país (Statista, 2019).

Tráfico global de datos móviles 2017-2022 (Statista, 2019).

Tráfico de datos móviles en todo el mundo 2017-2022, por región (Statista, 2019).

Tráfico global de datos móviles CAGR 2017-2022, por región (Statista, 2019).

Proporción del tráfico de Internet móvil en países seleccionados 2019 (Statista,2019).

Proporción del tráfico de internet móvil en las regiones globales 2019 (Statista, 2019).

Parte del tráfico global de productos web móviles 2015-2019 (Statista, 2019).

Países con la velocidad promedio de internet móvil más rápida 2019 (Statista, 2019).

Velocidad media global de descarga y carga de banda ancha móvil y fija en todo el mundo 2019 (Statista, 2019).

Uso diario de internet per cápita en todo el mundo 2011-2021, por dispositivo (Statista, 2019).

Aplicaciones móviles

Gasto anual del consumidor global de aplicaciones móviles 2018-2023, por tienda (Statista, 2019).

Descargas anuales de aplicaciones móviles mundiales 2018-2023, por tienda (Statista, 2019).

Número de aplicaciones disponibles en las principales tiendas de aplicaciones 2019 (Statista, 2019).

Categorías de aplicaciones móviles de más rápido crecimiento 2018 (Statista, 2019).

Aplicación móvil global retención de usuarios de tres meses y abandono 2018 (Statista, 2019).

Aplicaciones móviles: tasa de abandono 2012-2019 (Statista, 2019).

Ingresos globales de la tienda de aplicaciones de juegos y no juegos H1 2019 (Statista, 2019).

Principales aplicaciones de Android en todo el mundo 2019, por ingresos (Statista, 2019).

Principales aplicaciones de Android en todo el mundo 2019, por descargas (Statista, 2019).

Principales aplicaciones de iPhone en todo el mundo 2019, por ingresos (Statista, 2019).

Principales aplicaciones de iPhone en todo el mundo 2019, por descargas (Statista, 2019).

Principales aplicaciones de iPad en todo el mundo 2019, por ingresos (Statista, 2019).

Principales aplicaciones de iPad en todo el mundo 2019, por descargas (Statista, 2019).

Duración de la última sesión activa en aplicaciones en todo el mundo en 2017-2018, por categoría (Statista, 2019).

Duración promedio de las sesiones de participación en la aplicación 2017-2018, por región (Statista, 2019).

Móvil social

Tasa de penetración social móvil global 2019, por región (Statista, 2019).

Penetración activa de redes sociales móviles en las Américas 2019 (Statista, 2019).

Penetración activa de redes sociales móviles en países europeos 2018 (Statista, 2019).

Penetración activa de redes sociales móviles en los países MENA 2017 (Statista, 2019).

Penetración activa de redes sociales móviles en países seleccionados de Asia-Pacífico 2019 (Statista, 2019).

Redes sociales globales clasificadas por número de usuarios 2019 (Statista, 2019).

Las aplicaciones de mensajería móvil global más populares 2019 (Statista, 2019).

Principales aplicaciones de redes sociales para iPhone en todo el mundo 2019, por descargas (Statista, 2019).

Principales aplicaciones de redes sociales para iPhone en todo el mundo 2019, por ingresos (Statista, 2019).

Principales aplicaciones de comunicación de Android en todo el mundo 2019, por descargas (Statista, 2019).

Principales aplicaciones de comunicación de Android en todo el mundo 2019, por ingresos (Statista, 2019).

Número de usuarios activos mensuales de Instagram 2013-2018 (Statista, 2019).

Usuarios activos diarios de Snapchat 2014-2019 (Statista, 2019).

\section{Móvil media}

Principales aplicaciones de entretenimiento para iPhone en todo el mundo 2019, por descargas (Statista, 2019).

Principales aplicaciones de entretenimiento para iPhone en todo el mundo 2019, por ingresos (Statista, 2019). 


\begin{tabular}{|c|}
\hline Estadísticas del uso de Internet móvil en todo el mundo \\
\hline Principales aplicaciones de música de Android en todo el mundo 2019, por descargas (Statista, 2019). \\
\hline Principales aplicaciones de música de Android en todo el mundo 2019, por ingresos (Statista, 2019). \\
\hline Tráfico global de video móvil 2017-2022 (Statista, 2019). \\
\hline Dispositivos utilizados para ver videos en línea en todo el mundo 2018 (Statista, 2019). \\
\hline Dispositivos utilizados para ver videos en línea en todo el mundo 2018, por grupo de edad (Statista, 2019). \\
\hline Video play mundial móvil compartir 2013-2018 (Statista, 2019). \\
\hline Visores mundiales de videos de teléfonos móviles 2016-2021 (Statista, 2019). \\
\hline Comercio móvil \\
\hline Distribución de transacciones de consumo en todo el mundo 2018, por canal de pag \\
\hline Penetración global del uso de pagos móviles 2018, por región (Statista, 2019). \\
\hline Cuota de comercio electrónico de las ventas minoristas electrónicas 2018, por país (Statista, 2019). \\
\hline $\begin{array}{l}\text { Parte de los ingresos de la sesión de comercio electrónico en todo el mundo 2018, por fuente y medio (Statista, } \\
\text { 2019). }\end{array}$ \\
\hline Visitas y pedidos globales del producto web minorista en línea 2019, por dispositivo (Statista, 2019). \\
\hline Duración global de las visitas al producto web minorista en línea 2015-2019, por dispositivo (Statista, 2019). \\
\hline Valor global de pedido de compra en línea 2019, por dispositivo (Statista, 2019). \\
\hline Valor de orden de compra global en línea 2019, por plataforma (Statista, 2019). \\
\hline Principales tipos de aplicaciones minoristas en todo el mundo 2018 (Statista, 2019). \\
\hline $\begin{array}{l}\text { so global de dispositivos móviles de consumo para la investigación de productos en la tienda en } 20 \\
\text { í (Statista, 2019). }\end{array}$ \\
\hline
\end{tabular}

Se estima que el $80 \%$ de los usuarios se desconectarán de los productos web que no funcionan bien en su dispositivo. Además, los motores de búsqueda degradan activamente los productos web que no son aptos para dispositivos móviles en su algoritmo de clasificación, y podemos verificar si un producto web es apto para dispositivos móviles a los ojos de Google al realizar su prueba para dispositivos móviles. En general, los usuarios móviles son la mayoría, pero los usuarios de tabletas y computadoras de escritorio siguen siendo muy importantes. El $83 \%$ de los usuarios desean poder continuar su experiencia de mano en un dispositivo de escritorio, donde la usabilidad es a menudo mucho mejor (Schwarz, 2019).

Un estudio que tuvo como objetivo evaluar la calidad de la eXperiencia del usuario del diseño web responsivo en dispositivos móviles, recopiló datos de 156 estudiantes universitarios de Indonesia, a quienes se les pidió evaluar la eXperiencia del usuario del diseño web en uno de los siguientes escenarios: diseño web responsivo en entornos de escritorio y dispositivos móviles y diseño web no responsivo en entornos de dispositivos móviles. La calidad de la eXperiencia del usuario se midió observando el número de clics y desplazamientos, así como la calidad de la información que ha experimentado el usuario. Los resultados de la prueba ANOVA demostraron que el diseño web responsivo fue capaz de mantener la calidad de la eXperiencia del usuario del producto web en cuanto a la funcionalidad del hogar, la legibilidad del contenido y el disfrute del uso del producto web, pero no en la arquitectura de la información. Además, también se demostró que el RWD reduce la cantidad de desplazamiento al leer contenido. Sin embargo, requiere más desplazamiento y clic que el que no respondía al explorar su arquitectura de información (Sajid, 2018).

Si bien el diseño responsivo no garantiza una eXperiencia positiva del usuario al usar un producto, las estadísticas descriptas anteriormente, demuestran fehacientemente el crecimiento de la ingeniería móvil, y por tanto la importancia de un buen diseño responsivo lo que ayudará a que el usuario se sienta confortable al usar un producto web desde multidispositivos.

\section{EXPERIENCIA DE USUARIO Y CICLOS AGILES}


En esta sección se describe concisamente el marco teórico, referidos a la eXperiencia de usuario y ciclos ágiles, que fundamenta el trabajo a desarrollar.

\subsection{Experiencia de Usuario (UX)}

La "eXperiencia del usuario" abarca todos los aspectos de la interacción del usuario final con la empresa, sus servicios y sus productos (Norman Nielsen Group, 2019).

La International Organization for Standardization (ISO 9241-210-2019), define la eXperiencia de usuario como las percepciones y respuestas de las personas, resultantes del uso o anticipación de uso de un sistema, producto o servicio.

Nota 1: Las percepciones y respuestas de los usuarios incluye las emociones, creencias, preferencias, percepciones, confort, comportamientos y logros del usuario acaecidos antes, durante y después del uso.

Nota 2: La eXperiencia de Usuario es una consecuencia de la imagen de marca, presentación, funcionalidad, performance del sistema, comportamiento interactivo y las capacidades asistivas de un sistema, producto o servicio. Esto también resulta del estado internos y físicos resultantes de experiencias anteriores, actitudes, habilidades y personalidad, y del contexto de uso (ISO 9241-210-2019).

La UX es consecuencia de la imagen o marca, presentación, funcionalidad, rendimiento del sistema, comportamiento interactivo, capacidades de ayuda de un sistema interactivo. Es el estado interno y físico del usuario, resultado de sus experiencias previas, actitudes habilidades, personalidad y contexto de uso. Algunos autores consideran la UX como una extensión de la usabilidad (Departamento de Ingeniería Informpatica, Grupo de Interacción, Tecnologías y Educación, 2015).

\subsection{Modelos de procesos UX}

A continuación se describen brevemente las metodologías de desarrollo más reconocidas que consideran la eXperiencia de usuario, aunque ninguna de ellas incluye recomendaciones específicas respecto a cómo asegurar que el producto sea responsivo, en pos de mejorar la eXperiencia de usuario al interectuar con una aplicación.

\section{1- Diseño tradicional UI-UX Project:}

Hay muchas formas de definir y estructurar el proceso de diseño en función del tipo de empresa, el contexto y las necesidades del proyecto, pero en general el proceso de diseño en un proyecto digital estándar presenta las fases siguientes (Piñol, 2016):

1) Investigación, definición y estrategia.

2) Ideación y eXperiencia de usuario.

3) Diseño y desarrollo.

4) Revisión, análisis y soporte.

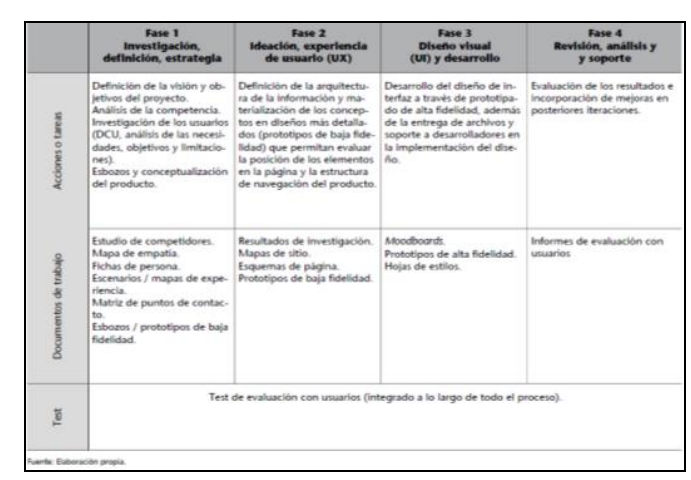

Figura 1. Elaboración propia de un proceso de diseño por Jordi Rovira Piñol (Piñol,2016).

El proceso de diseño de la UX es un método iterativo que ayuda a mejorar y pulir continuamente el diseño. Se ejecuta en diferentes etapas repetidamente mientras se evalúa el diseño en cada etapa, las cuales se muestran en el siguiente diagrama (Minhas, 2018): 
Figura 2. Etapas del Proceso de Diseño UX Tradicional (Minhas, 2018).

2.1- Entender el problema: Se analizan los requisitos con métodos de investigación de usuarios estándar de la industria, entrevistas, observación, sesiones de lluvia de ideas con los clientes, muestra de los productos existentes para obtener sus comentarios.

2.2- Investigar: Se centra en comprender la competencia del mercado, conocer su dominio y obtener inspiraciones e ideas de sus competidores.

2.3- Sketch: Implica la definición de IU de la característica requerida. Se dibujan bocetos en papel, flujos de pizarra blanca y marcos para compartir sus ideas con las partes interesadas. Esta etapa en sí misma es un proceso iterativo.

2.4- Diseño: Se convierten las maquetas y los wireframes iniciales en imágenes de excelente aspecto con el tema y los estilos aplicados. La preparación y el intercambio de especificaciones de diseño para el equipo de desarrollo también es parte de esta etapa.

2.5- Implementar: Se construye primero la funcionalidad de back-end y la conecta con la interfaz de usuario cuando obtienen artefactos de diseño.

2.6- Evaluar: Cuando se implementan las características del producto, el producto final se evalúa en función de si es utilizable; facilidad de uso; si proporciona la solución deseada a los usuarios; si el producto tiene la credibilidad que hace que alguien quiera usarlo debido a la experiencia que proporciona. El equipo de diseño valida el producto en términos de flujo de usuarios y experiencia e identifica áreas donde se necesitan mejoras.

2- The UX Book process and guidelines: El ciclo de vida propuesto consta de las siguientes etapas:

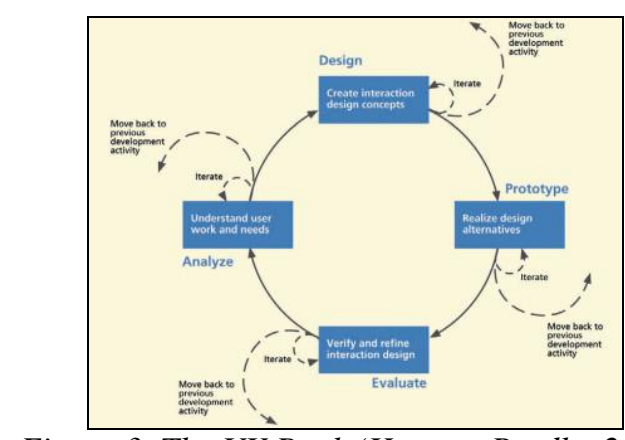

Figura 3. The UX Book (Hartson, Pardha,2012). 
3.1- Análisis: se centra en entender el trabajo y las necesidades del usuario:

- Investigación contextual.

- Análisis contextual.

- Necesidades y requerimientos de usuarios.

- Modelos de diseño de la información.

3.2- Diseño: se realiza el diseño conceptual, determinando el comportamiento de interacción y el look and feel.

3.3- Prototipo: la implementación de la aplicación, se basa en el prototipado.

3.4- Evaluación: se enfoca en validar y verificar si el diseño satisface las necesidades y requierimientos de los usuarios.

3- The Agile UX: Agile UX consta de 4 procesos y se basa en la prueba continua. Es decir, en adaptar el diseño a la eXperiencia de usuario de forma constante. Se basa en la colaboración, no en la documentación innecesaria, en la iteración continua y rápida para mejorar la UX, a través de sketching rápido y de test de usabilidad y usuarios.

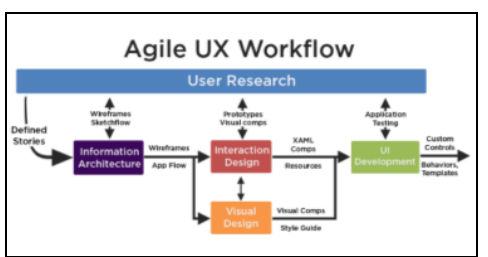

Figura 4. The Agile UX Workflow (Dpto. de Ing. Informática, 2015).

El proceso consta de las siguientes etapas (Forum, 2017):

4.1 Arquitectura de la información: se recoge información, buscando empatía; es decir, entender a nuestros clientes para saber qué y cómo vamos a ofrecerles la solución que necesitan, en pos de construir las historias de usuarios. Se elaboran wireframes HTML en bruto de las vistas.

4.2 Diseño de interacción: a partir de los wireframes se diseñan los prototipos.

4.3- Diseño visual: se centra en el aspecto visual de la página, tomando como entrada los wireframes y las componentes visuales definidas en la etapa anterior.

4.4- Desarrollo de interfaz de usuario: a partir del prototipo, las componentes visuales y guías de estilo, se construye y prueba la aplicación, y los clientes efectúan los controles necesarios. En la metodología de Agile UX, las pruebas son constantes, ya que se realizan a lo largo de cada sprint.

4- Lean Startup: se utilizan 3 técnicas Lean (UNIMOOC,2014):

- El diseño de Modelos de Negocio

- El Desarrollo de Clientes (una guía que permita saber qué pasos dar para construir un negocio nuevo.

- El Desarrollo Ágil (un método que permite, utilizando preferentemente herramientas gratuitas, producir software, productos físicos o servicios a partir de una idea: La fecha de lanzamiento del producto es el mismo día en que se piensa en él).

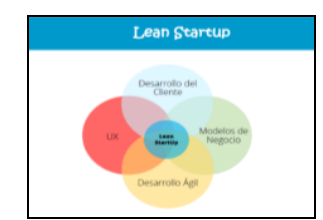

Figura 5.1. Bases de Lean Startup (Dpto. de Ing. Informática, 2015).

Su proceso consta en formular las ideas de negocio como hipótesis, hacer un experimento que nos lleve a pensar sobre la veracidad de nuestros supuestos y obtener de ellos datos o métricas que me ayuden a tomar decisiones. A su vez, si vemos este proceso en forma cíclica, podre- 
mos ir retroalimentando nuestro proyecto desde etapas tempranas hasta llegar a la propuesta de valor que más se adecue a nuestro mercado (Ordoñez, 2014).

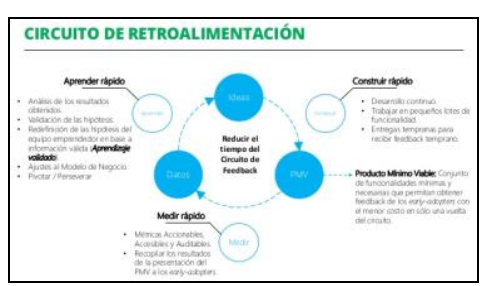

Figura 5.2. Proceso Lean Startup (Ordoñez, 2014).

A continuación se describirá más detalladamente el proceso Lean $U X$, puesto que entre todos los modelos de proceso presentados, se considera que es el óptimo para ser combinado con técnicas que incorporen las características de software responsivo. En la Sección 4 se fundamentará las razones por la cual se eligió dicho modelo.

5- Lean UX Process (Gothelf, 2013): La unión de Lean Startup y el diseño basado en la eXperiencia de usuario, es Lean UX. Los principios Lean subyacentes al Lean Startup se aplican a Lean UX de tres formas:

1- Primero, nos ayudan a eliminar los desechos de nuestro proceso de diseño de UX, alejándonos de la documentación fuerte y transportándonos a un proceso que crea sólo los artefactos de diseño que necesitamos para hacer avanzar el aprendizaje del equipo.

2- Segundo, nos impulsan a armonizar nuestro "sistema" de diseñadores, desarrolladores, gerentes de productos, ingenieros de aseguramiento de la calidad, comercializadores y otros en una colaboración transparente y multifuncional que brinda a los no diseñadores en nuestro proceso de diseño.

3- Por último, y quizás lo más importante, es la mentalidad. El cambio que ganamos al adoptar un modelo se basa en la experimentación. En lugar de confiar en un diseñador héroe para adivinar la mejor solución desde un solo punto de vista, se utiliza la experimentación rápida y la medición para aprender rápidamente qué tan bien (o no) nuestras ideas cumplen con nuestros objetivos.

Además de Lean Startup, Lean UX tiene otros dos fundamentos: el pensamiento de diseño y filosofías de desarrollo ágil.

Lean UX rompe las barreras que han mantenido a los diseñadores de software aislados de las necesidades comerciales reales, por un lado, y la implementación real, por otro. También trae a nuestros socios de negocios y tecnología a la pizarra para que trabajen con nosotros en las mejores soluciones de manera continua.

\subsection{Cimientos de Lean UX}

1- Design thinking: El pensamiento de diseño toma la posición explícita de que todos los aspectos de una empresa pueden abordarse con métodos de diseño. Le da a los diseñadores permiso y precedente para trabajar más allá de sus límites típicos. Alienta a los no diseñadores a usar métodos de diseño para resolver los problemas que enfrentan en sus roles.

2- Agile: Lean UX aplica los cuatro principios básicos del desarrollo Agile al diseño de productos:

a. Individuos e interacciones sobre procesos y herramientas. Para generar las mejores soluciones rápidamente, se involucra a todo el equipo. Las ideas se intercambian libremente y con frecuencia.

b. Software de trabajo sobre documentación completa. Cada problema de negocios tiene infinitas soluciones, y cada miembro de un equipo tendrá una opinión sobre cuál es la mejor. El desafío es averiguar qué solución es la más viable.

c. Colaboración del cliente sobre negociación de contrato. La colaboración con sus compañeros de equipo y clientes crea una comprensión compartida del espacio del problema y las soluciones propuestas. 
d. Respondiendo al cambio sobre la siguiente planificación. El supuesto en Lean UX es que los diseños iniciales del producto serán incorrectos, por lo que el objetivo debe ser averiguar qué es lo que está mal con ellos lo antes posible.

\subsection{Principios de Lean UX}

Lean UX se apoya en 15 principios, los cuales corresponden a los atributos que debe tener cualquier equipo que trabaje con Lean UX:

1- Equipos multifuncionales: Lean UX exige un alto nivel de colaboración entre estas disciplinas.

2- Equipos pequeños, dedicados y coubicados: se debe limitar el tamaño del equipo a no más de 10, con dedicación exclusiva para que las relaciones crezcan entre colegas.

3- Progreso es igual a resultados: se mide el progreso del proyecto según resultados del negocio, no los documentos. Si una característica no está funcionando bien, podemos tomar una decisión objetiva sobre si se debe mantener, cambiar o reemplazar.

4- Centrado en los problemas: el equipo se centra en resolver el problema del negocio y no limitarse a implementar un grupo de funciones. Si una característica no está funcionando bien, podemos tomar una decisión objetiva sobre si se debe mantener, cambiar o reemplazar.

5- Eliminación de residuos: Todo lo que no ayude a lograr mejores resultados debe eliminarse. Los recursos del equipo son limitados. Cuanto más desperdicio pueda eliminar el equipo, más rápido podrá moverse.

6- Lotes pequeños: El equipo debe crear los diseños necesarios para avanzar, evitando crear un gran stock de ideas. El diseño de lotes grandes hace que el equipo sea menos eficiente.

7- Descubrimiento continuo: Comprometer a los clientes con el proceso de diseño y desarrollo, mediante actividades programadas. El objetivo es comprender qué hacen los usuarios con sus productos y por qué lo hacen.

8-GOOB (Getting out of the building): Las respuestas sobre las necesidades de los usuarios están en el mercado, no en una oficina.

9- Entendimiento común: El conocimiento colectivo del equipo se construye a medida que se trabaja, y permite evitar la repetición para avanzar con eficacia.

10- Antimodelos (estrellas, gurús y ninjas): Lean UX aboga por una mentalidad basada en el equipo. Los expertos de toda condición rompen la cohesión del equipo y reducen la colaboración.

11- Exteriorización del trabajo: Exponer el trabajo de forma pública más allá del computador para mostrar a colegas y clientes.

12- Hacer en lugar de analizar: Hay más valor en crear la primera versión de una idea que en emplear tiempo debatiendo méritos propios.

13- Aprendizaje en lugar de crecimiento: $\mathrm{Al}$ asegurar que una idea funciona antes de hacerla crecer, se reduce el riesgo de los grandes despliegues de funciones.

14- Permiso para equivocarse: Para experimentar ideas y encontrar las mejores soluciones es necesario sentirse libre de equivocarse. El permiso para fracasar engendra una cultura de experimentación, que engendra creatividad y ésta a su vez, produce soluciones innovadoras.

15- Escapar de negocios basados en entregables: La atención debe estar enfocada en las funciones de mayor impacto. Los artefactos que el equipo usa para obtener ese conocimiento son irrelevantes. 


\subsection{Proceso Lean UX}

Las etapas de las cuales consta el proceso son:

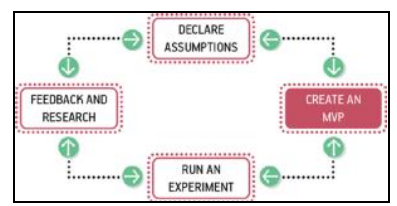

Figura 6. Lean UX Process (Gothelf, 2013).

6.1- Declarar suposiciones e hipótesis: Lean UX no inicia con requerimientos sino con supuestos, a partir de los cuales, se crean y validan hipótesis, en forma colaborativa entre los miembros del equipo. Las tareas que se llevan a cabo en esta etapa son:

1- Realizar la declaración del problema, y examinar los supuestos implícitos en él, para transformarlos en hipótesis. Se sugiere el uso de la plantilla Bussines Assumptions Worksheet.

2- Priorizar los supuestos con la matriz de priorización, de acuerdo al riesgo vinculados a ellos.

3- Transformar cada suposición en una declaración de hipótesis, especificando un mecanismo de validación.

4- Identificar los usuarios del sistema usando el método de protopersonas.

5- Definir las funciones a desarrollar, teniendo presente los resultados de las hipótesis y los usuarios de sistema. Se elabora una Tabla de creación de hipótesis, con las características, para quien y que resultado se obtendrá.

6- Diseñar colaborativamente: El diseño colaborativo permite a todo el equipo: crear juntos los conceptos del producto, construir un entendimiento común sobre el problema y las soluciones, con menos necesidades de documentar, decidir qué funcionalidad y elementos de la interfaz implementan mejor las funciones recogidas en las hipótesis.

- Lean UX promueve la conversación como método principal de comunicación entre los miembros del equipo.

- De manera de formalizar las sesiones que se consideren necesarias, se aplica la técnica, de Estudio de Diseño, que es una sesión más formal de trabajo.

- Otra herramienta que se considera, es la Guía de estilo, entendida como una biblioteca de patrones, un repositorio con los elementos de la interfaz aprobados y listos para funcionar.

- En el caso de que el equipo de trabajo se encuentre geográficamente distribuido, se sugiere el empleo de herramientas como Skype, Google Docs, Google Draws, Wikis, Teléfono con cámara. Si bien es mas compleja su aplicación, se puede hacer uso de la técnica Estudio de diseño.

6.2- Crear un PMV (producto mínimo viable): Se crea un PMV, es decir, el desarrollo más pequeño que pueda construirse para validar cada hipótesis, a través de experimentos. Este PMV es mostrado al cliente para tener un feedback y poder usar lo aprendido. Si la hipótesis es válida, hay que perfeccionarla; si es errónea, debe abandonarse. De esta forma se realiza la iteración y se comienza todo el proceso de nuevo. Para crear los PMV se preparan prototipos que le permita al usuario simular cómo será su experiencia en el uso del producto o servicio en cuestión. Dependiendo de su complejidad existen prototipos de baja, mediana y alta fidelidad. Algunas herramientas sugeridas para la creación de prototipos de baja fidelidad son: Balsamiq, Microsoft Visio, OmniGraffle (solo para mac), Microsoft Power Point, Fluid Designer/Pop prototype on paper. Para la obtención de prototipos de media y alta fidelidad, se sugiere: Axure RP, Adobe Fireworks, prototipos codificados.

6.3- Ejecutar un experimento: Los prototipos ayudan a mostrar a los stakeholders cómo va el progreso del producto. Cuánto más se exponga el PMV a las miradas ajenas, habrá más conocimiento para validarlo. No es necesario crear un prototipo de la experiencia completa del producto. En su lugar, se debe simular la parte más importante de la experiencia para su clien- 
te y su negocio. Los MVP pueden ser el envío de un email, una landing, un botón para medir cuánta gente lo pulsa y estaría interesada, etc. Al final depende de nuestra hipótesis y lo que queremos averiguar (si resuelve un problema real, si hay suficiente demanda, etc.)

6.4- Feedback e investigación: se llevan a cabo dos actividades principales en Lean UX:

- Descubrimiento colaborativo: se centra en que la investigación la realice el propio equipo, permitiendo que todos los miembros puedan observar y opinar cómo ha sido testeada la hipótesis.

- Descubrimiento continuo: la investigación es continua, lo escencial es lograr una participación fluida del cliente, en pos de minizar el tiempo en la creación de hipótesis, el diseño de experimentos y comentarios de los clientes, permitiendo validar de esta manera más rápido las hipótesis.

6.5 Integrando Lean UX y Agile: El modelo que propone Jeff Gothelf, es el siguiente:

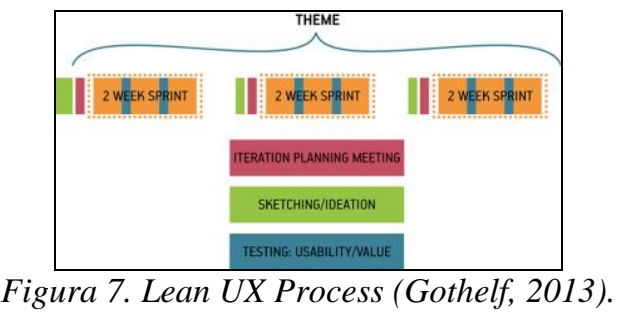

7.1- Sketching/Ideation: cada tema debe iniciarse con una serie de ejercicios de lluvia de ideas y validación, similares a las hipótesis. Estas actividades pueden ser tan cortas como una tarde o una semana. Se puede hacer con el equipo inmediato o con un grupo más amplio. El alcance del tema determinará la cantidad de participación y el tiempo que requieren estas actividades de lanzamiento. Las ideas se probarán, validarán y desarrollarán nuevos conocimientos. Se ejecutan sesiones de lluvia de ideas más cortas posteriores que se llevan a cabo antes de que comience cada nuevo sprint, lo que le permite al equipo utilizar la información más reciente para crear la acumulación de pedidos para el próximo sprint.

7.2- Iteration Planning Meeting: el resultado de la sesión de inicio debe llevarse a la reunión de planificación de la iteración (MIP). El desorden de notas adhesivas, bocetos, wireframes, prototipos de papel y cualquier otro artefacto puede parecer inútil para los observadores externos, pero será significativo para el equipo, que tiene la comprensión compartida necesaria para extraer historias de usuarios y priorizarlas.

7.3- Testing Usability/Value: Se planifican las sesiones de usuario cada semana. El equipo nunca estará a más de cinco días hábiles de la validación del cliente, pero aún así sus ideas tendrán tiempo suficiente para reaccionar antes del final del sprint. Se utilizan los artefactos creados en las sesiones de ideación como material base para las pruebas de usuario. Cuando las ideas son en bruto, se está probando el valor (es decir, ¿la gente quiere usar mi producto?). Una vez que se haya establecido un deseo para el producto, las pruebas posteriores con artefactos de mayor fidelidad revelarán si la solución es utilizable.

\section{DISEÑO WEB RESPONSIVO Y PROPUESTAS DE TRABAJO PARA SU APLICACION}

En esta sección se describe concisamente el marco teórico, referidos al diseño web responsivo y propuesta de trabajo para su aplicación, que fundamenta el trabajo a desarrollar.

\subsection{Diseño Web Responsivo (RWD)}

Este concepto surge en el año 2010 de la mano del diseñador web norteamericano Ethan Marcotte, donde el propone que en lugar de hacer diseños a medida y desconectados para cada uno de los siempre crecientes dispositivos web, podemos tratarlos como facetas de una misma 
experiencia. Podemos diseñar para una experiencia de observación óptima, pero incrustar tecnologías basadas en estándares dentro de nuestros diseños para hacerlos no sólo más flexibles, sino más adaptables al medio que los renderiza (Marcotte, 2010).

El diseño web responsivo (RWD) es un enfoque de desarrollo web que crea cambios dinámicos en la apariencia de un producto web, según el tamaño de la pantalla y la orientación del dispositivo que se usa para verlo. RWD utiliza los llamados puntos de interrupción para determinar cómo aparecerá el diseño de un producto: un diseño se utiliza sobre un punto de interrupción y otro diseño se aplica debajo de ese punto. Los puntos de interrupción se basan comúnmente en el ancho del navegador.

El mismo HTML se sirve a todos los dispositivos, utilizando CSS (que determina el diseño de la página web) para cambiar el aspecto de la página. En lugar de crear un producto separado y una base de código correspondiente para monitores de pantalla ancha, computadoras de escritorio, computadoras portátiles, tabletas y teléfonos de todos los tamaños, una única base de código puede admitir a los usuarios con vistas de diferentes tamaños.

RWD tiene ventajas potenciales sobre el desarrollo de productos separados para diferentes tipos de dispositivos. El uso de una base de código única puede hacer que el desarrollo sea más rápido, en comparación con el desarrollo de 3 o 4 productos distintos, y facilita el mantenimiento a lo largo del tiempo, ya que un conjunto de código y contenido debe actualizarse en lugar de 3 o 4.

RWD también es relativamente "futuro". "a prueba", ya que puede admitir nuevos puntos de interrupción necesarios en cualquier momento, porque no vincula el diseño a un dispositivo en particular. Cuando los elementos se mueven alrededor de la página, la eXperiencia del usuario puede ser completamente diferente de una vista del producto a la siguiente. Es importante que los equipos de diseño y desarrollo trabajen juntos no solo para determinar cómo se debe barajar el contenido, sino también para ver cómo se ve el resultado final de ese cambio y cómo afecta la eXperiencia del usuario.

Muchos equipos recurren a marcos de diseño responsivos populares, como Bootstrap para ayudar a crear diseños. Tales marcos pueden ser de gran ayuda para moverse a lo largo del desarrollo. Sin embargo, se debe considerar cuidadosamente cómo funcionará el marco con el contenido y la funcionalidad del producto, en lugar de su funcionamiento en general.

Se deben tener en cuenta las siguientes consideraciones:

1- Realizar pruebas del diseño responsivo en distintas plataformas.

2- Priorizar el contenido, en pos de ayudar a los usuarios a encontrar lo que necesitan de manera más eficiente.

3- Performance: el rendimiento puede ser un problema para el diseño responsivo porque se entrega el mismo código a todos los dispositivos, independientemente de si el código se aplica a ese diseño o no. Esto puede atascar el rendimiento en un teléfono inteligente, que puede depender de una conexión de datos más lenta y más rápida. Esta es la razón por la que algunos productos recurren al diseño adaptable, donde el servidor que aloja el producto web detecta el dispositivo que realiza la solicitud y entrega diferentes lotes de código HTML basados en ese dispositivo (Nielsen Norman Group, 2014).

\subsubsection{Ventajas del RWD respecto a la accesibilidad (Carreras, 2014)}

1- El contenido y la presentación están separados, los estilos están definidos en las CSS y no se usan tablas para maquetar. Todo ello beneficia a las personas con diferentes discapacidades al permitir a los agentes de usuario adaptar el contenido de acuerdo a sus necesidades (criterio de conformidad 1.3.1, [WCAG2, 2008])

2- Tendencia a un mayor respeto por los estándares web, lo cual maximizará la compatibilidad con las aplicaciones de usuario actuales y futuras, incluyendo las ayudas técnicas (pauta 4.1, [WCAG2, 2008]) 
3- Tendencia a tener la información estructurada y jerarquizada más correctamente (criterio de conformidad 1.3.1, [WCAG2, 2008])

4- Tendencia al uso de elementos semánticos para poder definir sus estilos en las CSS. Indicar explícitamente la función estructural o valor semántico del contenido permitirá que esta información se pueda determinar mediante software favoreciendo la accesibilidad (criterio de conformidad 1.3.1, [WCAG2, 2008])

5- El diseño flexible y la definición de tamaños relativos permiten que el texto se pueda ampliar sin desbordamientos y hacer zoom con garantías (criterio de conformidad 1.4.4, [WCAG2, 2008])

- El tamaño flexible de las imágenes y vídeos permitirá que se adapten mejor al espacio disponible sin que se superpongan con otros contenidos.

- Mejor eXperiencia para los usuarios con baja visión que suelen tener resoluciones de pantalla más bajas y suelen ampliar la pantalla.

6- Además, el diseño flexible y que no se usen tablas para maquetar ayuda a garantizar un orden de lectura correcto. Los diseños fluidos tienden a presentar el contenido en el mismo orden que el DOM y este es el mismo orden en que, por ejemplo, los lectores de pantalla leerán el contenido (criterio de conformidad 1.3.2, [WCAG2, 2008])

7- Se tiene muy presente que el producto se visualizará en distintos dispositivos y por tanto:

- Es más probable que el producto no sea operable solo con el ratón, la forma de interactuar ahora es muy variable y esto ayuda al diseño inclusivo (principio Operable, [WCAG2, 2008])

- Es más probable que se mejore el contraste de color, que suele ser más pobre en los dispositivos móviles ya que bajamos el brillo para ahorrar batería, además de que son habituales los reflejos en la pantalla (criterios de conformidad 1.4.3 y 1.4.6, [WCAG2, 2008])

- Mayor uso de la técnica Progressive Enhancement (Mejora Progresiva) que consiste en una implementación básica, que funciona a través de múltiples dispositivos y con una amplia gama de tecnologías de asistencia, añadiendo después más funcionalidades para los dispositivos que las soportan.

8- Focalizarse solo en lo necesario, priorizar y simplificar, dará como resultado productos más fáciles de navegar y entender, con menor carga cognitiva y visual, mejorando la legibilidad y la accesibilidad.

Mayor uso de la técnica Progressive Disclosure (Revelación Progresiva), que se basa en diferenciar el contenido primario del secundario. El contenido primario aparece inmediatamente en el flujo normal de la página y es muy visible. El objetivo es mostrar solo lo relevante para el usuario en este momento. Nos beneficia a todos, pero especialmente a los usuarios con discapacidad cognitiva o con déficit de atención, y bien hecho facilita la navegación a los usuarios de lectores de pantalla o a las personas con discapacidad motora.

\subsubsection{Malas prácticas en Responsive Design (Carreras, 2014)}

Al comprobar la accesibilidad en las diferentes resoluciones establecidas mediante media Query, nos encontramos que muchas veces se ocultan contenidos en las versiones para tamaños de pantalla más pequeños. Para que determinado contenido no se muestre, a veces lo ocultan con estilos definidos en la CSS para las resoluciones más bajas. Otras veces se hace detectando el dispositivo desde el servidor o por javascript. Todo eso no es Responsive Design, pero son prácticas habituales que, mal hechas, suelen generar problemas de accesibilidad. Generalmente, estos errores se encuentren no cuando se accede a la página con el mayor tamaño o resolución, sino cuando se reduce la resolución o tamaño de pantalla, y que son consecuencia de la ocultación de contenido mal implementado o sin medir sus consecuencias, entre ellos:

- Los encabezados ya no tienen una jerarquía correcta.

- Enlaces para saltar el contenido, al ocultarlo generan ruido. 
- El contenido se oculta de forma inadecuada.

- El menú de navegación es diferente.

\subsection{Propuestas de trabajo para RWD}

Con la aparición de la filosofía de Diseño Web Responsivo, se construyeron diversos flujos de trabajo, herramientas y/ técnias, que aseguran que un producto sea responsivo. A continuación se describen los principales encontrados, a partir del análisis del arte realizado:

\section{1- Flujo de trabajo de Viljami Salminem (Viljami, 2012)}

El siguiente diagrama describe las etapas propuestas por el flujo de trabajo:

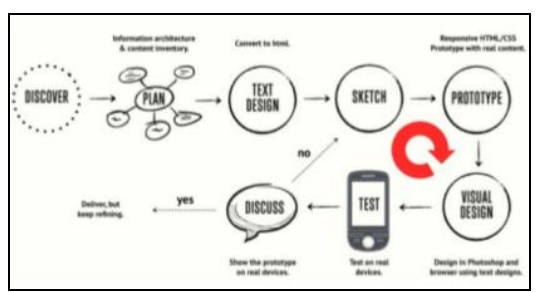

Figura 8. Flujo de trabajo de Viljami Salminem (Beati, 2013).

8.1- Discover: se recopila información para conocer al cliente.

8.2- Plan: se refina el concepto, trabajando en la arquitectura de la información y construyendo las historias de los usuarios; estableciendo y describiendo los elementos de contenido, que luego se califican según su nivel de importancia. Sobre la base de esa importancia, podemos hacer wireframes HTML en bruto de las vistas.

8.3- Text Design: escribimos (diseñamos) todos los contenidos del producto web en forma de texto.

A menudo se hace este paso en HTML sin estilos, ya que podemos ver instantáneamente cómo aparece el contenido en un diseño estrecho de una sola columna y si el orden es correcto. Este paso también es posible de lograr utilizando documentos de texto que funcionan de manera similar.

8.4- Sketch (bocetos): dibujar ideas es algo que se debe hacer y es especialmente importante antes de ir al navegador. Se prueban los bocetos usando los diseños de texto HTML del paso anterior (lo que significa que se agregan algunas reglas de CSS sobre ellos).

8.5- Prototype: es necesario crear prototipos temprano en HTML/CSS ya que es la única forma de ver realmente cómo responderá el diseño a diferentes tipos de dispositivos. Se trabaja en "gráficos de punto de interrupción" antes del prototipo o diseño real. A continuación se muestra un diagrama de punto de interrupción del dispositivo basado en el diseño de respuesta pragmática de Stephanie Rieger y Diagrama de dispositivo simple de Metal Toad.

8.6- Visual Design: este paso ocurre en iteraciones antes y después del prototipado. Se puede usar Photoshop para hacer la mayor parte del diseño, o en un navegador. Puede ser el navegador, Photoshop, Fireworks, InDesign o cualquier otra cosa que se sienta bien.

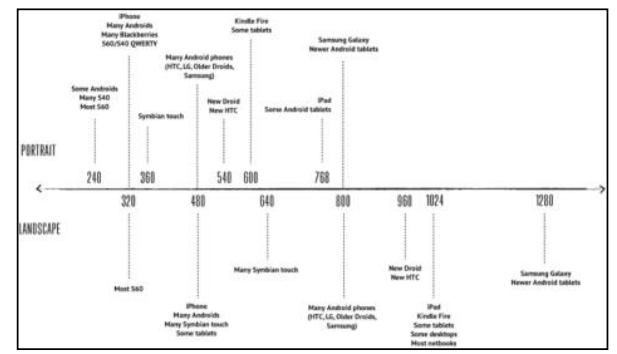

Figura 9. Device-map-2012 (Viljami 8.7- Test: Mediante el diagrama de puntos de corte del dispositivo se pueden agregar todas las peculiaridades del navegador. Las pruebas también deben incluir pruebas de los usuarios, ya que es la forma más sencilla de ver cómo funciona realmente el prototipo en términos de usabilidad y qué partes de este podrían necesitar trabajo.

8.8- Discuss: Discutir con el cliente durante todas las iteraciones. Presentar los prototipos HTML reales al cliente y mostrar cómo funcionan en los dispositivos reales.

8.9- Iterate: Ejecutar el flujo de trabajo sketch $\rightarrow$ prototype $\rightarrow$ design $\rightarrow$ test $\rightarrow$ discuss hasta que funcione. 
Respecto al proceso expuesto se observa que el diseño responsivo se considera recién en la etapa de prototipado, cuando existen otras estrategias que pueden aplicarse antes de llegar a esta instancia en el desarrollo del producto, como lo propuesto por en el flujo de trabajo de Pon Kattera. Por otro lado, la iteración del flujo de trabajo sketch $\rightarrow$ prototype $\rightarrow$ design $\rightarrow$ test $\rightarrow$ discuss, se centra en la modificación del diseño responsivo en forma simultánea con la del refinamiento del producto en su totalidad.

2- Hernán Beati propone una nueva metodología de diseño de una plantilla web: Presenta similitudes al proceso anterior, pero la principal diferencia rige en la forma de bocetar la página y cómo codificarla. Las etapas son las siguientes (Beati, 2013):

1- Priorización de contenidos:

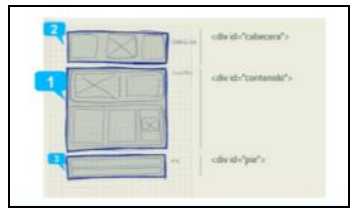

Figura 10.1. Priorización de contenidos (Beati, 2013).

2- Sketch: con los contenidos priorizados para una plantilla, se boceta de mayor a menor y se codifica de menor a mayor. Al bocetar se debe considerar qué deja de flotar en cada breakpoint.

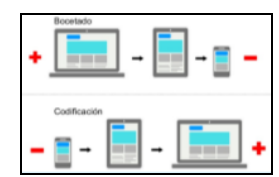

Figura 10.2. Bocetado y codificación (Beati, 2013).

- Se sugiere usar una grilla de 1000px de ancho, para que pueda pasarse a porcentajes fácilmente, $1000 \mathrm{px}=100 \%$.

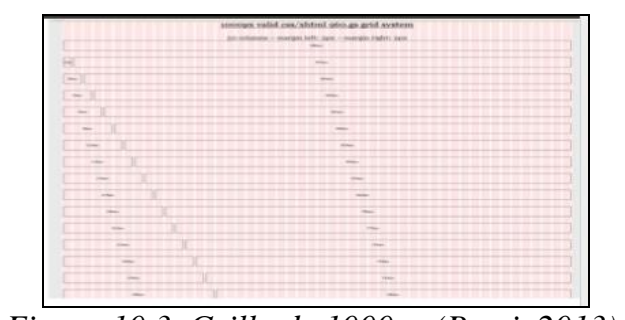

Figura 10.3. Grilla de 1000px (Beati, 2013).

3- Para la definición de cada breakpoint, el contenido decide; es decir que se estira la ventana hasta romper el diseño y medir.

4- Repetir las acciones a, b y c mencionadas en el punto 2).

5- Probar cada boceto hasta los extremos:

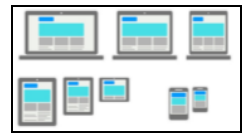

Figura 10.4. Prueba de bocetos (Beati, 2013).

6- El usuario da su aprobación a un prototipo HTML, por ejemplo con UXPin, o se vuelve a modificar hasta su aprobación.

7- Se codifica de menor a mayor (Mobile first).

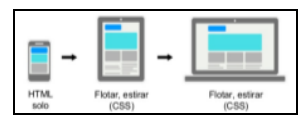

Figura 10.5. Codificación de menor a mayor (Beati, 2013).

8- Se sugiere diseñar en el navegador.

9- Se sugiere diseñar los textos con Typecast: 


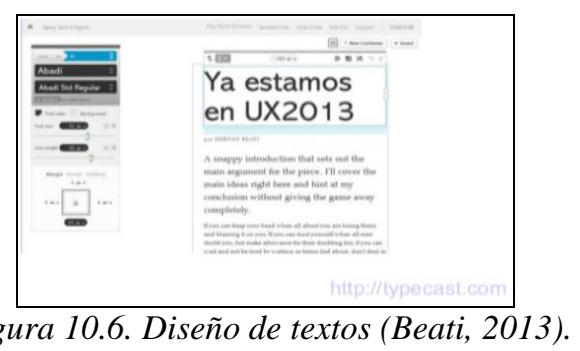

10- Medir las zonas de imágenes y hacer lista de tamaños. Medirlas en extremo mínimo y máximo. Ir haciendo listas por cada breakpoint de: tamaños de columnas, márgenes y paddings; tamaños de tipografías; tamaños de imágentes,etc.

11- El usuario da su aprobación a un prototipo HTML (ya con CSS incluido) y se vuelve a modificar hasta su aprobación. Se hace mantenimiento hasta el fin del proyecto.

12- Se documenta.

13- Se recomienda usar el sistema de grillas sólo para el prototipado, no para producción. Puesto que en marcos similares a Boostrap, es necesario ser riguroso en la eliminación de CSS y Javascript no utilizados, o se terminará creando una experiencia pesada y lenta para los usuarios.

3- Flujo de trabajo "Diseño responsivo prágmático" de Stephanie Rieger: el enfoque al igual que los procesos anteriores se centra en primero el contenido, y se basa en la definición de visual mockups que luego serán prototipados (live responsive mockup), definiendo en la hoja de estilo puntos de interrupción (breakpoints) mayores para cambios en el diseño; y menores para cambios en componentes específicas. Luego este prototipo será probado para determinar el rendimiento, impacto de las capacidades nativas y las condiciones de la ventanas (Rieger, 2011).

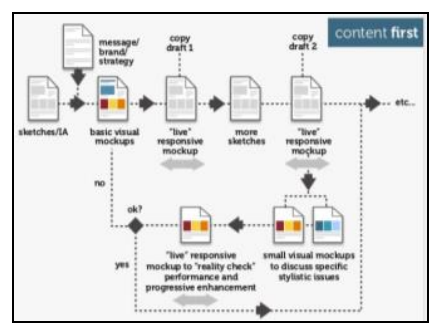

Figura 11.1. Diseño Responsivo Pragmático (Rieger, 2011).

- Difiere de la metodología Mobile first, el enfoque sostiene que hay que iniciar un diseño simple sin media query. Esto es para asegurar que la página esté disponible para aquellos navegadores que no soportan media query, por eso sugiere iniciar con diseño ligero que contenga los estilos por defecto de navegación, fuentes y contenidos.

- Por otro lado sugiere no limitarse al intercambio de posibles hojas de estilo, sino dejar la hoja de estilo en cascada, lo que resulta en una stylesheet más pequeña, argumentando que menos duplicación en las declaraciones aumenta la eficiencia del navegador.

- Plantea que no debe mantenerse una stylesheet que incluya estilos innecesarios para todos los dispositivos, cuando sólo se descargará uno específico.

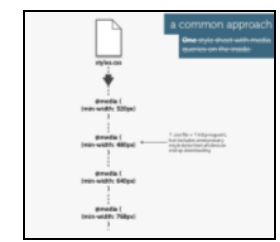

Figura 11.2. Unica stylesheet con mediaqueries (Rieger, 2011).

El plantea que una solución más óptima es definir múltiples hojas de estilo con mediaqueries: 


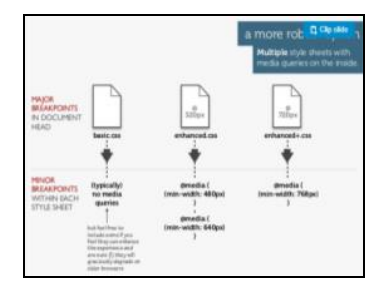

Figura 11.3. Múltiples stylesheets con mediaqueries (Rieger, 2011).

Tambien menciona que tener múltiples hojas de estilo causa múltiples http requests, por lo que la performance se verá afectada, dependiendo de como se optimice el código, de lo que se solicite en cada request, librerías, utilidades, etc.

Un ejemplo de major y minor breakpoints, sería:

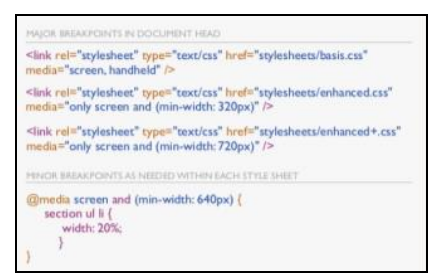

Figura 11.4. Definición de major y minor breakpoints (Rieger, 2011).

La definición de los breakpoints se debe basar en las necesidades del diseño y la legibilidad, ancho y naturaleza del contenido.

Se sugiere ser pragmático y definir puntos de interrupción aunque no sean usados por un dispositivo en particular.

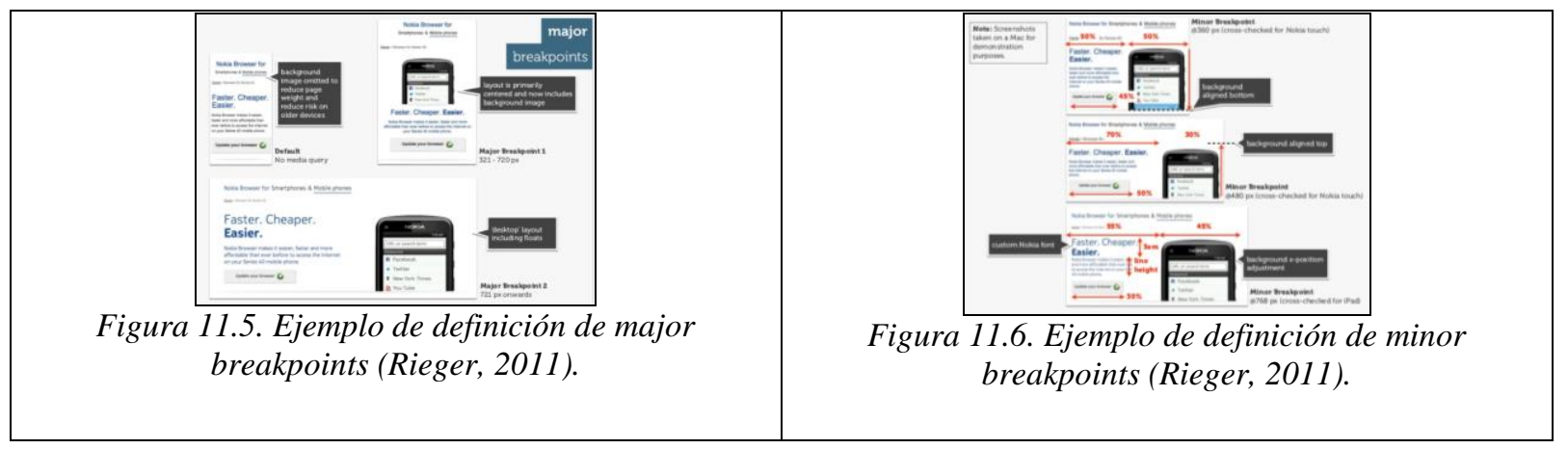

- Si bien el tamaño de pantalla es unos de los aspectos a considerar para un diseño responsivo, hay que tener en cuenta también que éste se alinee con las capacidades del navegador o dispositivo.

Es decir, que un buen diseño responsivo considera la detección de características de la pantalla y del navegador del dispositivo.

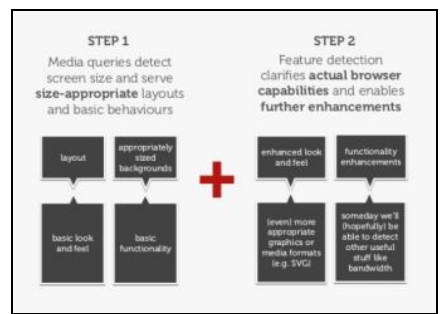

Figura 11.7. Consideraciones para un diseño responsivo (Rieger, 2011).

Para detectar estas características se pueden usar Client-side features detection como herramienta; o base de datos de dispositivos, user agent strings y el propio conocimiento tácito del desarrollador (porque algunos navegadores mienten).

- Otro aspecto a considerar para el diseño responsivo, es optimizar la front-end perfomance. Una forma es optimizando el manejo de las técnicas responsivas de imágenes, que común- 
mente se manejan en el lado del cliente, pero cuando los dispositivos están restringidos se sugiere manejarlas tanto desde el lado del cliente como del servidor:

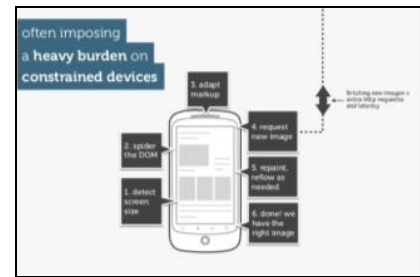

Figura 11.8. Imagen demasiado pesado para ser manejada por el cliente (Rieger, 2011).

Una estrategia propuesta desde el lado del servidor sería:

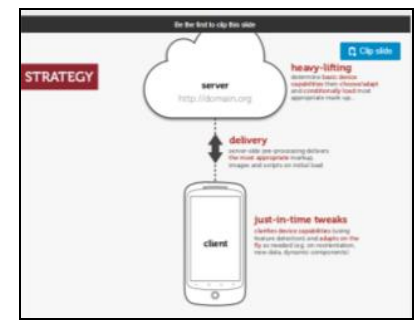

Figura 11.9. Técnica para el manejo de imágenes responsivas (Rieger, 2011).

- Por último, se sugiere modelar una estrategia móvil, como por ejemplo la siguiente:

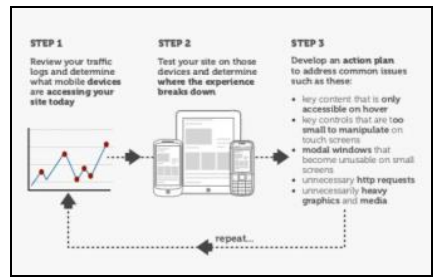

Figura 11.10. Definición de estrategia móvil (Rieger, 2011).

A continuación se describirá más detalladamente el flujo de trabajo de Pon Kattera, puesto que entre todos los flujos de trabajo presentados, se considera que es el óptimo para ser combinado con un proceso de desarrollo que considere la eXperiencia de usuario. En la Sección 4 se fundamentará las razones por la cual se eligió dicho flujo de trabajo.

4- Flujo de trabajo de Pon Kattera: el enfoque se centra en Mobile first (content first) responsive web design, enfocándose en los usuarios y el contenido primero antes de dibujar las pantallas móviles, pero le agrega otras características que permiten iniciar un proyecto responsivo. A continuación se describe el enfoque (Kattera, 2012):

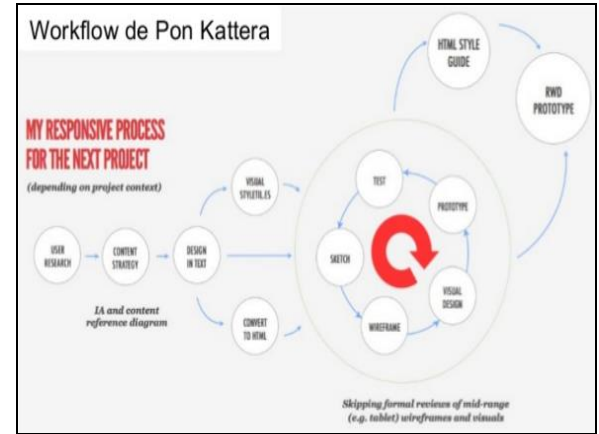

Figura 12: Responsive Process Pon Kattera (Beati, 2013).

12.1- User research: El objetivo es obtener una mejor comprensión de los negocios del cliente, la competencia y los principales objetivos del proyecto. Durante esta etapa, se construyen 
las historias de usuarios y se identifican los distintos esenarios en la que se empleará la futura aplicación.

12.2- Content: se determina el contexto del dispositivo. Es importante no confundir dicho contexto con la intención del usuario, es decir no porque el usuario se encuentre en un dispositivo más pequeño significa que quiere "hacer menos". Los usuarios móviles deben poder hacer lo que los usuarios de escritorio puedan hacer, siempre y cuando se los presente en una manera usable.

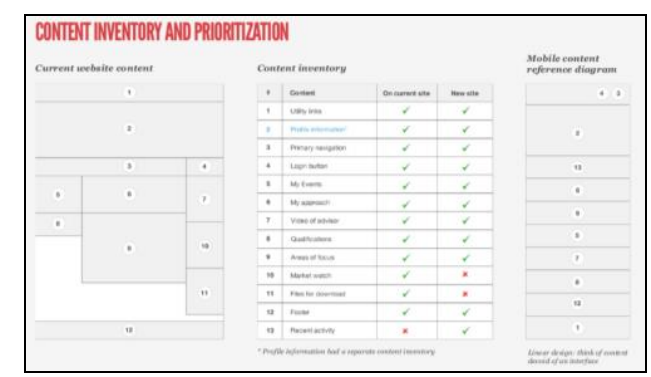

Figura 13: Ejemplo de content website and content inventory (Beati, 2013).

12.3- Design in text: se centra en escribir el contenido de cada página en forma textual. El texto debe comunicar la escencia de la página herramientas como Markdown y Pandoc ayudan a convertir archivos de texto a HTML.

12.4- Stylestiles: Ethan Marcotte se refiere a composiciones estáticas durante el proceso de diseño responsivo como un "catálogo de suposiciones" Las fichas de estilo son el complemento perfecto para ese catálogo, ya sea en lugar de composiciones o para reforzar los temas visuales. Las fichas de estilo no implican dimensiones ni dispositivo; solo que el diseño será digital. Además de Style Tiles (Warren, 2011), las "Guías de estilo de componentes" pueden ayudar a llevar un estilo particular a través de funcionalidades específicas sin diseñar páginas web completas. Estas guías son muy útiles para diseños responsivos en una gran cantidad de dispositivos y para implementar sistemas de diseño para una Plataforma CMS.

12.5- Designing in the browser: consiste en crear elementos y estilos en HTML/CSS. Lo más importante es usar una herramienta que no contenga nuestra creatividad, pudiendo ser el navegador, Photoshop, Fireworks, InDesign o cualquiera que nos haga sentir bien"-Viljami Salminen, en su flujo responsivo.

Consiste en la aplicación de patrones de diseño y guías de estilo HTML, que nos ayuden a facilitar el diseño de la página.

12.6- Diseño y desarrollo iterativo:

a- Diseño de interacción: consiste en la elaboración de bocetos, wireframes y prototipos.

b- Diseño visual: se enfoca en el aspecto visual de la página, empleando lenguajes visuales y grillas para la determinación de las proporciones que deben considerarse para los distintos dispositivos.

c- Iterative design and development process breakdown:

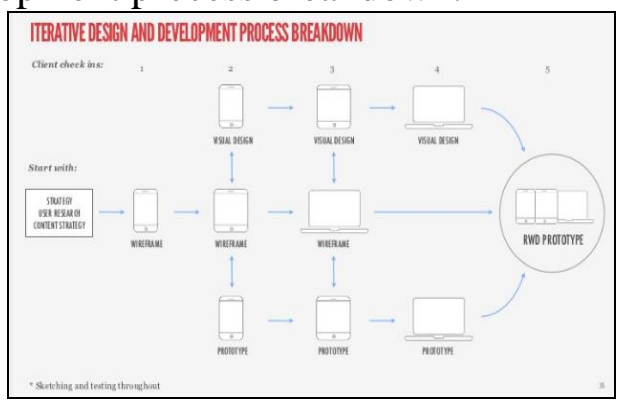

Figura 14: Iterative design and development process breakdown (Kattera, 2013).

A diferencia del flujo de trabajo de Viljami Salminem, Pon Kattera se enfoca en los usuarios y el contenido primero antes de dibujar las pantallas móviles, pero le agrega otras características 
que permiten iniciar un proyecto responsivo, mediante el uso de stylestiles, propuesto por la diseñadora Samantha Warren, que se basa en la completitud de una plantilla que permite resolver el problema de pasar de los borradores o wireframing iniciales al boceto en photoshop. En ella podemos avanzar sobre los aspectos visuales del producto como paletas de colores, texturas, tipografía y logotipo sin necesidad de diseñar completamente la página.

\section{NUESTRA PROPUESTA}

Analizadas las metodologías ágiles que consideran la eXperiencia de usuario y los flujos de trabajo que aseguran que el producto resultante sea responsivo, y con el propósito de proponer un enfoque integrado que combine ambas características, se arriba a las siguientes consideraciones:

\subsection{Respecto a la elección de la metodología de diseño que considera la UX}

Se considera que Lean $U X$ es el proceso óptimo para incorporar las actividades necesarias que aseguren que el producto resultante sea responsivo, debido a que:

(i) emplea los principios de Lean Startup para aplicarlos en un contexto de diseño desde la eXperiencia de usuario, y combina cimientos de la metodología Design Thinking con los 4 principios básicos del desarrollo agil, priorizando la creación de un entendimiento común de la eXperiencia de usuario que se está diseñando, para lo cual sólo se crea la documentación necesaria para el aprendizaje del equipo. Es decir que abarca las actividades propuestas por otras metodologías; (ii) rompe las barreras que han mantenido a los diseñadores de software aislados de las necesidades comerciales reales, por un lado, y la implementación real, por otro. También trae a nuestros socios de negocios y tecnología a la pizarra para que trabajen con nosotros en las mejores soluciones de manera continua.

\subsection{Respecto a la elección del flujo de trabajo responsivo}

Se considera que el flujo de trabajo responsivo propuesto por Pon Kattera es más completo, ya que no sólo se enfoca en la etapa de prototipado para lograr un diseño responsivo, sino que a diferencia del resto de los enfoques propuestos, lo aborda en el diseño de interacción y visual.

Del flujo responsivo pragmático ideado por Stephanie Rieger, se consideran algunas de las estrategias propuestas por el autor para construir y optimizar un diseño responsivo, entre ellas la definición de puntos de interrupción, en lugar de lo propuesto por Pon Kattera ya que se manejan con porcentajes y no con pixeles; la definición de múltiples hojas de estilo y el manejo de imágenes responsivas.

\subsection{Respecto de las herramientas, plantillas y técnicas para el diseño responsivo}

Se considera que la plantilla propuesta por Hernán Beati, es óptima respecto a la forma de bocetar la página y cómo codificarla, argumentando que la complejidad al realizar el sketch, consiste en determinar qué componente dejar de flotar en cada breakpoint. Además la grilla se construye en base a porcentajes y no en pixeles como propone Pon Kattera. Por lo cual se empleará dicha forma de construir la grilla y no la propuesta por Pon Kattera.

\subsection{Nuestro enfoque customizado}

Tal como señalamos, nuestro objetivo se orienta en proponer un enfoque customizado cuyos cimientos sean las etapas de desarrollo propuestas por Lean UX, e incorporando las recomendaciones respecto a características de diseño responsivo contempladas en el flujo de trabajo ideado por Pon Kattera. A su vez, se propone customizar dicho flujo incorporando algunas de las pautas sugeridas por Hernán Beati y Stephanie Rieger.

A partir de lo mencionado, proponemos un ciclo de prototipado basado en el proceso de Lean UX. La ejecución de los 4 pasos propuestos por esta metodología, son customizados para que el enfoque de desarrollo de un producto incorpore las actividades necesarias para lograr un diseño responsivo, lo que supone una buena eXperiencia de usuario. 
La Figura 15, ilustra nuestro enfoque resultante, el cual está: (i) basado en la metodología ágil Lean UX (figura 6.); (ii) incorpora las actividades para diseñar un producto responsivo propuestas por Pon Kattera (figura 12) y aplica técnicas de diseño responsivo propuestas por Hernan Beati y Stephanie Rieger. A los efectos de asistir a la comprensión del enfoque propuesto, aplicamos la notación compuesta por el número de figura seguido por el número de paso para identificar a cada paso; por ejemplo, Figura 15.1, hace referencia al paso 1 de la Figura 15.

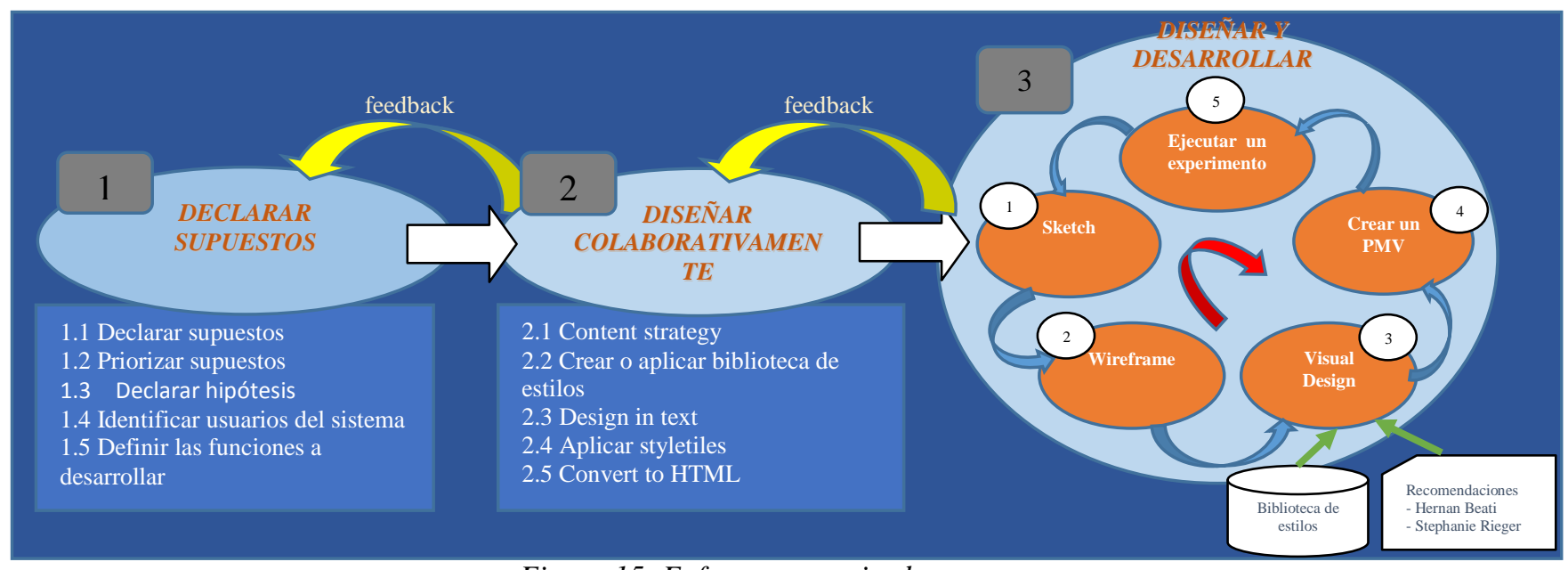

Figura 15: Enfoque customizado.

En la figura 15.1, se customiza el Paso 1 - Declarar supuestos, de la metodología Lean UX (figura 6) en 5 actividades: (15.1.1) Declarar supuestos; (15.1.2) Priorizar supuestos; (15.1.3) Declarar hipótesis; (15.1.4) Identificar usuarios del sistema y (15.1.5) Definir las funciones a desarrollar. A continuación se describen las herramientas que se emplearán para llevar adelante cada una de estas actividades:

Tabla 2: Herramientas a utilizar en el Paso 1 de Nuestro Enfoque.

\begin{tabular}{|c|c|c|}
\hline $\begin{array}{l}\text { Etapa 1: Declarar suposiciones e } \\
\text { hipótesis }\end{array}$ & $\begin{array}{l}\text { Herramientas propuestas por } \\
\text { Lean UX que serán aplicadas }\end{array}$ & Herramientas sugeridas \\
\hline 1.1- Declarar supuestos & Business Assumptions Worksheet & - \\
\hline 1.2- Priorizar supuestos & Matriz de riesgos & - \\
\hline 1.3- Declarar hipótesis & $\begin{array}{l}\text { Formato propuesto por Lean UX: } \\
\text { We believe [this statement is } \\
\text { true]. } \\
\text { We will know we're [right/wrong] } \\
\text { when we see the following feed- } \\
\text { back } \\
\text { from the market: } \\
\text { [qualitative feedback] and/or } \\
\text { [quantitative feedback] and/or } \\
\text { [key } \\
\text { performance indicator change]. }\end{array}$ & \\
\hline $\begin{array}{l}\text { 1.4- Identificar los usuarios del } \\
\text { sistema }\end{array}$ & $\begin{array}{l}\text { Construir los protopersonas, para } \\
\text { lo cual se puede realizar un brai- } \\
\text { nstorming con todo el equipo de } \\
\text { trabajo. Se empleará la plantilla de } \\
\text { Persona Format. }\end{array}$ & $\begin{array}{l}\text { - Mapa de empatía } \\
\text { - Guía útil que resume los diez } \\
\text { elementos principales que una } \\
\text { ficha de persona debe contener, por } \\
\text { Silvana Churruca, especialista en } \\
\text { UX. } \\
\text {-Xtensio }\end{array}$ \\
\hline $\begin{array}{l}\text { 1.5- Definir las funciones a desa- } \\
\text { rrollar }\end{array}$ & Tabla de creación de hipótesis & - \\
\hline
\end{tabular}


La actividad 6 del Paso 1, propuesta por Lean UX se explota como una nueva etapa, dando por resultado al Paso 2 - Diseñar colaborativamente, el cual incorpora tres de las actividades propuestas por Pon Kattera en su flujo responsivo, siendo éstas: (15.2.1) Content strategy; (15.2.3) Design in text ; (15.2.4) Aplicar styletiles y (15.2.5) Convert to HTML. Por otro lado mantiene la actividad propuesta por Lean UX, (15.2.2) Crear o aplicar biblioteca de estilos. A continuación se describen las herramientas que se emplearán para llevar adelante cada una de estas actividades:

Tabla 3: Herramientas a utilizar en el Paso 2 de Nuestro Enfoque.

\begin{tabular}{|c|c|c|}
\hline $\begin{array}{l}\text { Etapa 2: Diseñar colaborativa- } \\
\text { mente }\end{array}$ & $\begin{array}{l}\text { Herramientas/Técnicas por Lean } \\
\text { UX y Pon Kattera que serán } \\
\text { aplicadas }\end{array}$ & Herramientas sugeridas \\
\hline 2.1-Content strategy & $\begin{array}{l}\text { 1. Se empleará la herramienta más } \\
\text { poderosa propuesta por Lean UX, } \\
\text { que es la conversación entre los } \\
\text { miembros del equipo. } \\
\text { 2. Se empleará la plantilla propues- } \\
\text { ta por Pon Kattera, para determinar } \\
\text { el contexto del dispositivo, identifi- } \\
\text { cando si es que existiera el conte- } \\
\text { nido actual del producto; definien- } \\
\text { do la estructura actual y la esperada } \\
\text { para el nuevo producto; y descri- } \\
\text { biéndolas en un diagrama de refe- } \\
\text { rencia de contenido móvil. } \\
\text { 3. Se crearán wireframes de baja } \\
\text { fidelidad } \\
\text { 4. Se realizarán estudios de Diseño } \\
\text { (para sesiones que requieran mayor } \\
\text { formalidad). Se empleará la planti- } \\
\text { lla A 6-up template, sugerida por } \\
\text { Lean UX. }\end{array}$ & $\begin{array}{l}\text { UXPin } \\
\text { Balsamiq } \\
\text { Moqups }\end{array}$ \\
\hline $\begin{array}{l}\text { 2.2- Crear o aplicar biblioteca de } \\
\text { estilos }\end{array}$ & $\begin{array}{l}\text { 1. Se creará o aplicará la guía de } \\
\text { estilo (biblioteca de patrones). } \\
\text { sugerida por Lean UX. } \\
\text { 2. Se utilizarán los styletiles sugeri- } \\
\text { dos por Pon Kattera, desarrollados } \\
\text { por Samantha Warren. }\end{array}$ & \\
\hline 2.3-Design in text & & HTML sin estilos \\
\hline 2.4- Convert to HTML & $\begin{array}{l}\text { Se empleará la gúia de estilo y } \\
\text { styletiles, definidos en el paso } 2.2 \text {. }\end{array}$ & \\
\hline
\end{tabular}

El resultado de este paso, sirve de entrada para la tercera etapa, donde se customizan las etapas 3 y 4 propuestas por Lean UX y se unifican en el Paso 3 - Diseñar y desarrollar iterativamente, incorporando a su vez las actividades propuetas por Pon Kattera para diseño responsivo.

El Paso 3, consta de las siguientes actividades: (15.3.1) Sketch; (15.3.2 Wireframes); (15.3.3) Visual Design; (15.3.4) Crear un PMV y (15.3.5) Ejecutar un experimento.

Esta etapa se basa en un bucle iterativo e incremental destinado a producir los prototipos de baja fidelidad y/o de alta fidelidad, según el tipo de desarrollo.

A continuación se describen las herramientas que se emplearán para llevar adelante cada una de estas actividades:

Tabla 4: Herramientas a utilizar en el Paso 3 de Nuestro Enfoque. 


\begin{tabular}{|c|c|c|}
\hline $\begin{array}{l}\text { Etapa 3: Diseñar y desarrollar } \\
\text { iterativamente }\end{array}$ & $\begin{array}{l}\text { Herramientas/Técnicas por Lean } \\
\text { UX, Pon Kattera, H. Beati y S. } \\
\text { Rieger, que serán aplicadas }\end{array}$ & Herramientas sugeridas \\
\hline 3.1- Sketch & - & - \\
\hline 3.2- Wireframes & $\begin{array}{l}\text { Se bocetará de mayor a menor, } \\
\text { según lo argumentado por Hernán } \\
\text { Beati, quien indica que la compleji- } \\
\text { dad se centra en qué componente } \\
\text { dejar flotar en cada breakpoint. }\end{array}$ & $\begin{array}{l}\text { Wireframes creados a mano } \\
\text { Balsamiq Mockups } \\
\text { Mockflow }\end{array}$ \\
\hline 3.3- Visual Design & 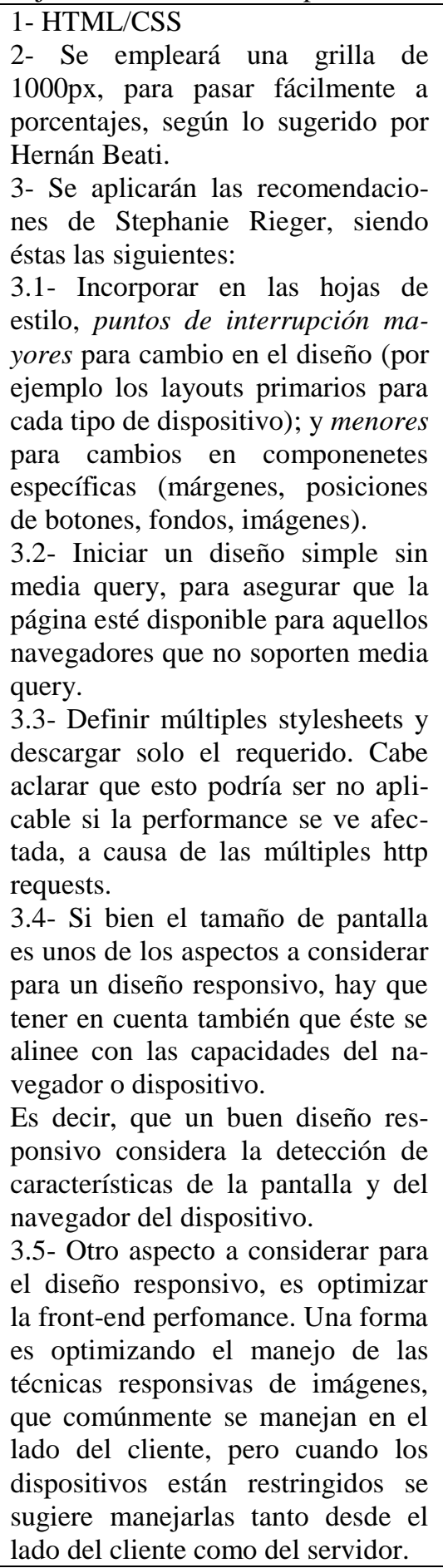 & \\
\hline 3.4- Crear un PMV & $\begin{array}{l}\text { 1- Hernán Beati sugiere: } \\
\text { 1.1- Codificar de menor a mayor } \\
\text { (Mobile first), ya que la compleji- } \\
\text { dad se centra en el diseño responsi- }\end{array}$ & $\begin{array}{l}\text { Prototipo de baja fidelidad: Mar- } \\
\text { vel. } \\
\text { Prototipo de alta fidelidad: Pro- }\end{array}$ \\
\hline
\end{tabular}




\begin{tabular}{|c|c|c|}
\hline $\begin{array}{l}\text { Etapa 3: Diseñar y desarrollar } \\
\text { iterativamente }\end{array}$ & $\begin{array}{l}\text { Herramientas/Técnicas por Lean } \\
\text { UX, Pon Kattera, H. Beati y S. } \\
\text { Rieger, que serán aplicadas }\end{array}$ & Herramientas sugeridas \\
\hline & $\begin{array}{l}\text { vo. } \\
\text { 1.2- Usar el sistema de grillas sólo } \\
\text { para el prototipado, no para produc- } \\
\text { ción. Puesto que en marcos simila- } \\
\text { res a Boostrap, es necesario ser } \\
\text { riguroso en la eliminación de CSS y } \\
\text { Javascript no utilizados, o se termi- } \\
\text { nará creando una experiencia pesa- } \\
\text { da y lenta para los usuarios. } \\
\text { 2- Lean UX sugiere: } \\
\text { 2.1- Para construir prototipos de } \\
\text { baja fidelidad: Balsamiq, Microsoft } \\
\text { Visio, OmniGraffle (solo para } \\
\text { mac), Microsoft Power Point, Fluid } \\
\text { Designer/Pop prototype on paper. } \\
\text { 2.2- Para la obtención de prototipos } \\
\text { de media y alta fidelidad: Axure } \\
\text { RP, Adobe Fireworks, prototipos } \\
\text { codificados. }\end{array}$ & $\begin{array}{l}\text { to.io } \\
\text { Axure prototipado de baja y alta } \\
\text { fidelidad. } \\
\text { Pencil project }\end{array}$ \\
\hline 3.5- Ejecutar un experimento & $\begin{array}{l}\text { - Mediante el diagrama de puntos } \\
\text { de corte del dispositivo se pueden } \\
\text { agregar todas las peculiaridades del } \\
\text { navegador. }\end{array}$ & $\begin{array}{l}\text { Marvel } \\
\text { Lookback }\end{array}$ \\
\hline
\end{tabular}

\subsubsection{Aplicación de nuestro enfoque customizado}

El proceso inicia con la declaración de un conjunto de supuestos, lo cuales son priorizados, en pos de declarar las hipótesis a ser validadas. Los usuarios serán identificados y las funciones a desarrollar se definen en esta etapa. Para llevar adelante estas actividades, se emplearán las herramientas y/o técnicas descriptas en la tabla 2. Una vez identificadas las funciones a desarrollar, se ejecutará el paso 2, donde se determinará el contexto del dispositivo, y se iniciarán actividades propias del diseño, para lo cual se definirán estilos propios o styletiles, se trasladarán las funciones en texto plano, y se empleara alguna de las herramientas propuestas en la tabla 3, para convertirlo a HTML. En la etapa 3, las funciones convertidas a texto plano, serán bocetadas en un sketch preliminar, el cual servirá de entrada para la elaboración del wireframe que permita obtener una mejor distribución del contenido deseado. Este contenido será probado visualmente, aplicando las guías de estilo definidas, breakpoints y recomendaciones sugeridas para asegurar que sea responsivo, descriptas en la tabla 4 . En este paso, tambien se desarrollarán prototipos de baja y/o alta fidelidad según lo requiera el tipo de producto a desarrollar, utilizando alguna de las herramientas sugeridas en la tabla 4, como por ejemplo on un prototipo de baja fidelidad, usando la herramienta Balsamiq Mockups o Axure.

El feedback obtenido permite validar el listado de hipótesis y determinar la continuidad (o no) del prototipo propuesto. De acuerdo al resultado obtenido en la validación de las hipótesis, se procede a mejorar el prototipo, o se plantea la revisión del listado de supuestos, según corresponda. Por otro lado, se indica un segundo bucle en la Etapa 3, esto es porque se aplican las actividades para obtener un diseño responsivo, que puede implicar o no la modificación del listado de hipótesis original. El entregable que resulta de ejecutar el bucle del Paso 3, es un prototipo con RWD.

\section{CONCLUSIONES Y TRABAJO FUTURO}


En el presente trabajo de investigación se realiza un profundo análisis de propuestas destinadas a incluir UX o RWD en el desarrollo de productos web. Este análisis es la base a partir de la cual se propone un enfoque integrado, que permita llevar adelante la construcción de un producto diseñado bajo los lineamientos propuestos por el diseño responsivo y que además considere la eXperiencia de usuario. De esta manera, basados en la hipótesis de que el diseño responsivo contribuye a mejorar la UX en el desarrollo de producto web, el enfoque ensambla los beneficios del desarrollo multidispositivo en el ciclo de diseño UX. En la Sección 4 de este documento se presenta y explica el enfoque, cuyos cimientos son las etapas de desarrollo propuestas por Lean UX. Estas etapas, se customizan para incorporar recomendaciones y técnicas de RWD, correspondientes a: (i) el flujo de trabajo ideado por Pon Kattera y; (ii) las propuestas de Hernán Beati y Stephanie Rieger. Sin embargo, en esta instancia de la investigación, el enfoque integrado presentado, es sólo una propuesta. En trabajo futuro, es necesario fortalecer y aplicar el enfoque integrado en diferentes dominios, para demostrar cómo el diseño responsivo ensamblado en ciclo ágiles UX, puede propiciar la eXperiencia de usuario en el desarrollo de productos web.

\section{REFERENCIAS}

BEATI, H. (2013) Hacia una metodología de Diseño Web Responsive, disponible en https://es.slideshare.net/hbeati/hacia-una-metodologa-de-diseo-web-responsive, accedido: Octubre 2019.

CARRERA, O. (2014) Responsive Design y accesibilidad. Buenas y malas prácticas. Errores comunes, disponible en https://olgacarreras.blogspot.com/2014/01/responsive-design-yaccesibilidad.html, accedido: Octubre 2019.

CLEMENT, J. (2019) Mobile internet usage worldwide - Statistics \& Facts, disponible en https://www.statista.com/topics/779/mobile-internet/, accedido: Octubre 2019.

DEPARTAMENTO DE INGENIERÍA INFORMÁTICA, Grupo de Interacción, Tecnologías y Educación (2015), Metodologías ágiles y UX. Lean UX, disponible en https://docplayer.es/4076753-Metodologias-agiles-y-ux-lean-ux.html, accedido: Octubre 2019.

FORUM, M. (2017) Las 4 fases del Agile UX: mejora la experiencia de usuario, disponible en https://www.martechforum.com/articulo/agile-ux/, accedido: Octubre 2019.

GOTHELF , J. (2013) Material proporcionado por la cátedra: Lean UX.

HARTSON R., PARDHA S. P. (2012) Material proporcionado por la cátedra: The_UX_Book_Process_an(BookZZ.org).pdf.

HIDAYANTO, A. N. (2014) Analysis of User Experience Quality on Responsive Web Design from its Informative Perspective, disponible en https://www.researchgate.net/publication/268808298_Analysis_of_User_Experience_Qual ity_on_Responsive_Web_Design_from_its_Informative_Perspective, accedido: Octubre 2019. 
ISO 9241-210-2019, disponible en https://www.iso.org/obp/ui/\#iso:std:iso:9241:-210:ed2:v1:en, accedido: Octubre 2019.

KATTERA, P. (2012) Design Process in the Responsive Age, disponible en https://www.slideshare.net/pkattera/design-process-for-responsive-web-design, accedido: Octubre 2019.

MARCOTTE, E. (2010) Responsive Web Design, disponible en https://alistapart.com/article/responsive-web-design/, accedido: Octubre 2019.

MINHAS, S. (2018) User Experience Design Process, disponible en https://uxplanet.org/userexperience-design-process-d91df1a45916, accedido: Octubre 2019.

NN/G NIELSEN NORMAN GROUP (2019) The definition of user experience (UX), disponible en https://www.nngroup.com/articles/definition-user-experience/, accedido: Octubre 2019.

NN/G NIELSEN NORMAN GROUP (2014) Responsive Web Design (RWD) and User Experience, disponible en https://www.nngroup.com/articles/responsive-web-designdefinition/, accedido: Octubre 2019.

ORDOÑEZ, J. (2014) Lean StartUp y Scrum. Como crear productos que los clientes quieran pagar, disponible en https://es.slideshare.net/JohnnyDark/lean-start-up-y-scrum-comocrear-productos-que-los-clientes-quieren-pagar, accedido: Octubre 2019.

PIÑOL, J. R. (2016) Material proporcionado por la cátedra: M5 PID_00245737.pdf.

RIEGER, S. (2011) Pragmatic Responsive Design, disponible en https://www.slideshare.net/yiibu/pragmatic-responsive-design, accedido: Octubre 2019.

SAJID, A. (2018) The Users Experience Quality of Responsive web Design on Multiple Devices, disponible en https://www.researchgate.net/publication/327329078_The_users_experience_quality_of_re sponsive_web_design_on_multiple_devices, accedido: Octubre 2019.

SALMINEN, V. (2012) Responsive Workflow, disponible en https://viljamis.com/2012/responsive-workflow/, accedido: Octubre 2019.

SCHWARZ, D. (2019) A guide to responsive design + breakpoints, disponible en https://uxtricks.design/blogs/ux-design/responsive-design/, accedido: Octubre 2019.

UNIMOOC (2014) The Lean Startup, disponible en https://unimooc.com/que-es-lean-startup/, accedido: Octubre 2019.

WARREN, S. (2011) StyleTiles, disponible en http://styletil.es/, accedido: Octubre 2019. 